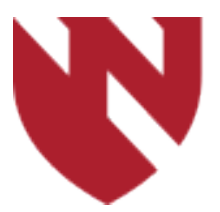

October 2021

\title{
Mycobacterium avium Pulmonary Infection Disguised as a Urinary Tract Infection
}

Megan Rolfzen

University of Nebraska Medical Center

Allison Ashford

UNMC

Tell us how you used this information in this short survey.

Follow this and additional works at: https://digitalcommons.unmc.edu/gmerj

Part of the Bacterial Infections and Mycoses Commons, Disorders of Environmental Origin Commons, Higher Education Commons, Internal Medicine Commons, and the Respiratory Tract Diseases Commons

\section{Recommended Citation}

Rolfzen ML, Ashford AK. Mycobacterium avium Pulmonary Infection Disguised as a Urinary Tract Infection. Graduate Medical Education Research Journal. 2020; 1(3).

This Case Report is brought to you for free and open access by DigitalCommons@UNMC. It has been accepted for inclusion in Graduate Medical Education Research Journal by an authorized editor of DigitalCommons@UNMC. For more information, please contact digitalcommons@unmc.edu. 


\title{
Mycobacterium avium Pulmonary Infection Disguised as a Urinary Tract Infection
}

\begin{abstract}
In the United States, Mycobacterium avium complex (MAC) has been found to be the most common isolate in non-tuberculous disease, and pulmonary infection is the most frequent presentation. It is ubiquitous in the environment, particularly in soil and manufactured water supply sources. Worldwide, $M$. avium infections, both pulmonary and disseminated, are steadily increasing. Due to MAC's ability to cause non-specific symptoms and its pervasiveness within the environment, it is paramount to incorporate this diagnosis in the differential, especially in those most susceptible. We report a case of a Mycobacterium avium complex pulmonary infection in 72-year-old Caucasian male with history of chronic immunosuppression and large hiatal hernia, highlight the imaging features, and discuss the importance of maintaining awareness in immunocompromised hosts.
\end{abstract}

\section{Keywords}

Immunosuppression, Nontuberculous Mycobacterium, Tree-in-Bud Opacities

Creative Commons License (c) (i) (9)

This work is licensed under a Creative Commons Attribution-Noncommercial-No Derivative Works 4.0 License. 


\section{Mycobacterium avium Pulmonary Infection Disguised as a Urinary Tract Infection \\ Megan Rolfzen', Allison Ashford²}

${ }^{1}$ University of Nebraska Medical Center, College of Medicine, Department of Anesthesiology

${ }^{2}$ University of Nebraska Medical Center, College of Medicine, Department of Internal Medicine

https://doi.org/10.32873/unmc.dc.gmerj.3.1.011

\section{Case}

A 72-year-old Caucasian man was admitted to the hospital after a week of progressively worsening encephalopathy, weakness, and malaise. His past medical history was significant for end stage renal disease status post bilateral renal transplants with one remaining kidney on chronic immunosuppression, recurrent urothelial cancer, hypertension, gastroesophageal reflux disease with a large intrathoracic hiatal hernia, and primary hyperparathyroidism. Medications taken at home included amlodipine, apixaban, aspirin, atorvastatin, furosemide, hydralazine, metoprolol tartrate, mycophenolate, pantoprazole, phenazopyridine, prednisone, and tacrolimus. On examination, he appeared cachectic and fatigued. Lung sounds were diminished in the bilateral bases. Palpation of the epigastric abdominal region revealed a hernia, and his left lower quadrant was slightly tender. During work-up of his nonspecific symptoms, his creatinine was found to be mildly elevated to 1.93 (baseline, 1.4-1.6), and his urine culture was positive for pansensitive Enterococcus faecalis. He clinically improved on ceftriaxone before switching to fosfomycin to complete an antibiotic regimen based on sensitivities. Coincidentally, during evaluation of his vague left lower quadrant pain, an abdominal x-ray exhibited imaging abnormalities in his lung bases that were further clarified as worsening tree-in-bud opacities and mild bronchiectasis in bibasilar lung fields on a dedicated chest computed tomography image (Fig. 1). Upon further questioning, he admitted to increased dyspnea and cough with sporadic choking events over the past few months and one episode of hemoptysis. Given his immunocompromised state, a bronchoscopy with bronchoalveolar lavage was performed which ultimately revealed Mycobacterium avium pulmonary infection.

\section{Discussion}

Mycobacterium avium is a member of the M. avium complex (MAC) which consists of the four Mycobacterium subspecies: avium, hominissuis, silvaticum, paratuberculosis. In the U.S., MAC has been found to be the most common isolate in non-tuberculous disease, and pulmonary infection is the most frequent presentation. ${ }^{2} \mathrm{MAC}$ infection can have protean manifestations based on the host immune environment, bacterial species, and organ affected. Signs and symptoms can include but are not limited to fever, localized lymphadenitis, cough, fatigue, hemoptysis, adenopathy, anemia, abdominal pain and diarrhea. Pulmonary disease typically occurs in patients with deficient cellular immunity or chronic lung disease. Radiographic findings are diverse and can include bronchiectasis, infiltrates in the upper lobes, nodules, and tree-in bud opacities. ${ }^{3}$ Studies utilizing high resolution CT have described up to $90 \%$ of cases of noncavitary MAC pulmonary disease having multifocal bronchiectasis and small $(<5 \mathrm{~mm})$ nodules in associated areas of the lung. ${ }^{4}$ According to a joint statement by the American Thoracic Society and Infectious Diseases Society of American, patients presenting with bronchiectasis are recommended to undergo a three-times weekly regimen of a macrolide, rifampin, and ethambutol for 3-6 weeks. ${ }^{1}$

In this case, chronic immunosuppression in the setting of prior kidney transplantation compromised the host's immune response to infection. However, prevention often proves difficult due to MAC's ubiquitous nature, particularly in soil and manufactured water supply sources. ${ }^{5}$ Mullis and Falkinham found that billions of mycobacteria exist as biofilms in typical household pipes composed of many different surfaces (i.e., copper, glass, zinc-galvanized steel, and PVC) ${ }^{6}$ Much research has been published on the dispersion and aerosolization of these bacteria through shower heads, water heater systems, humidifiers, and hot tubs. ${ }^{7}$ An additional, more esoteric source, is likely aspiration via gastric reflux. Thomson et al. elucidated that patients with MAC pulmonary disease had a higher incidence of gastroesophageal reflux disease than in matched MAC-negative controls. ${ }^{8}$ The aforementioned patient had a large known hiatal hernia seen on imaging and described active gastroesophageal reflux-type symptoms for which he was scheduled for surgical evaluation.

Worldwide, it is apparent that M. avium infections are steadily increasing. ${ }^{9,10}$ However, reporting non-tuberculous disease is not mandatory in many countries and states, making incidence and prevalence comparisons in distinct geographical regions difficult to study. One explanation for this increase 

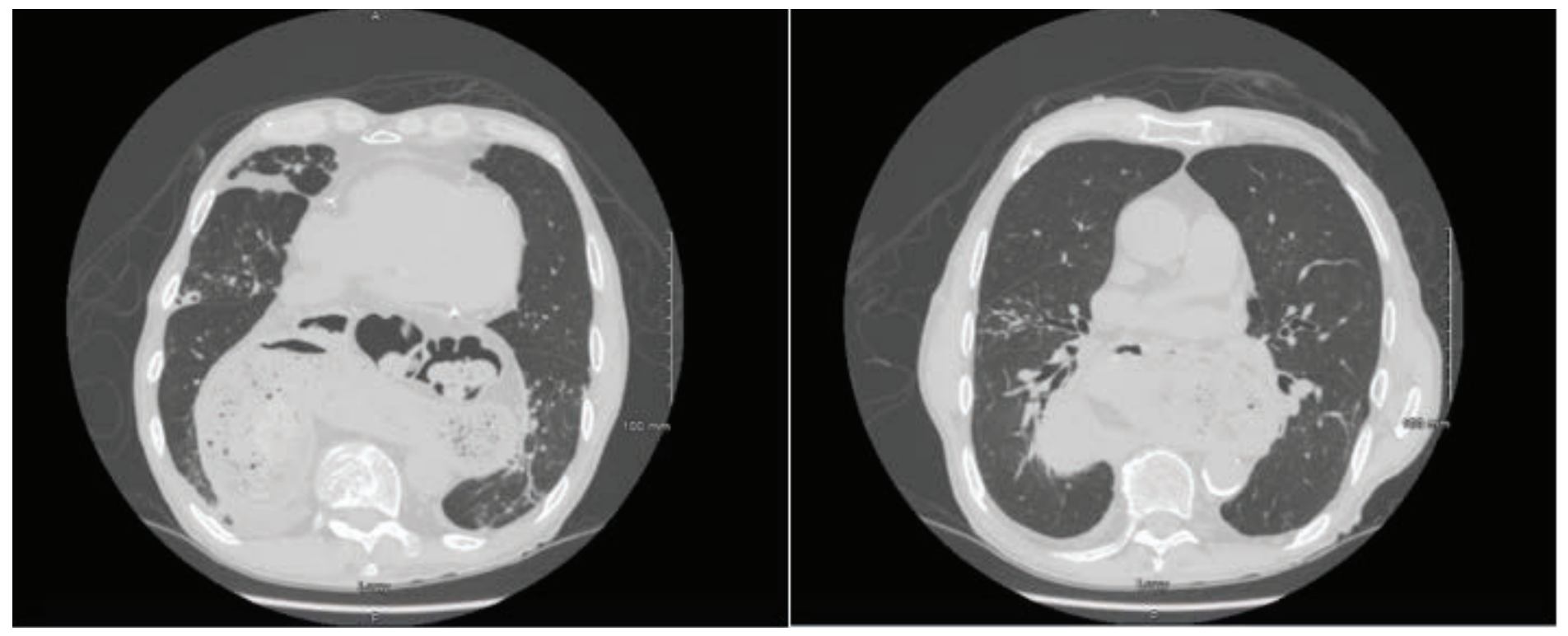

Figure 1. Axial non-contrast CT images of the chest showing a large hiatal hernia, multifocal bronchiectasis with multiple small nodules, and tree-in-bud opacities in the mid- and lower lung regions. Imaging findings are varied in MAC pulmonary infections but prominent bronchiectasis is often described.

could be due to improvement of diagnostic capabilities and greater awareness in the healthcare setting..$^{10}$ Alternatively, it may be due to an expanding portion of the population that is defined as immunosuppressed from regimens imposed after transplantation, chronic infection or inflammation, or simply senescence. Whether it be from increased scrutiny or the increasing prevalence of immunocompromised states it is safe to assume that cases of NTM will continue to rise.

\section{Conclusion}

The immunocompromised state is commonly encountered by the internist. It is important to keep a wide differential in the immunocompromised patient who presents with non-specific symptoms. Among nontuberculous mycobacterium, Mycobacterium avium is the most common cause of pulmonary disease worldwide as it is ubiquitous in the environment. ${ }^{2}$ Symptoms are variable based on pre-existing disease, but cough, fatigue, malaise, weakness, dyspnea, and hemoptysis are common. Typically, symptoms persist for a significant period of time before the diagnosis is made, which contributes to decreased quality of life and increased healthcare burden. Clinicians should maintain heightened awareness in immunocompromised patients.

\section{References}

1 Griffith DE, Aksamit T, Brown-Elliott BA, et al. An Official ATS/IDSA Statement: Diagnosis, Treatment, and Prevention of Nontuberculous Mycobacterial Diseases. Am J Respir Crit Care Med. 2007;175(4):367-416. doi:10.1164/rccm.200604$571 \mathrm{ST}$

2 O'Brien DP, Currie BJ, Krause VL. Nontuberculous Mycobacterial Disease in Northern Australia: A Case Series and Review of the Literature. Clin Infect Dis. 2000;31(4):958-967. doi:10.1086/318136

3 Cho JL, McDermott S, Tsibris AM, Mark EJ. Case 37-2015. New England Journal of Medicine. 2015;373(22):2162-2172. doi:10.1056/ NEJMcpc1504839

4 Moore EH. Atypical mycobacterial infection in the lung: CT appearance. Radiology. 1993;187(3):777782. doi:10.1148/radiology.187.3.8497629

5 Falkinham JO. Reducing Human Exposure to Mycobacterium avium. Annals ATS. 2013;10(4):378382. doi:10.1513/AnnalsATS.201301-013FR

6 Mullis SN, Falkinham JO. Adherence and biofilm formation of Mycobacterium avium, Mycobacterium intracellulare and Mycobacterium abscessus to household plumbing materials. Journal of Applied Microbiology. 2013;115(3):908-914. doi:https://doi. org/10.1111/jam. 12272

7 Feazel LM, Baumgartner LK, Peterson KL, Frank DN, Harris JK, Pace NR. Opportunistic pathogens enriched in showerhead biofilms. Proc Natl Acad Sci U S A. 2009;106(38):16393-16399. doi:10.1073/ pnas.0908446106

8 Thomson RM, Armstrong JG, Looke DF. Gastroesophageal Reflux Disease, Acid Suppression, and Mycobacterium avium Complex Pulmonary Disease. Chest. 2007;131(4):1166-1172. doi:10.1378/ chest.06-1906

9 Namkoong H, Kurashima A, Morimoto K, et al. Epidemiology of Pulmonary Nontuberculous Mycobacterial Disease, Japan. Emerging Infectious Diseases. 2016;22(6):1116-1117. doi:10.3201/ eid2206.151086

10 Busatto C, Vianna JS, da Silva LV, Ramis IB, da Silva PEA. Mycobacterium avium: an overview. Tuberculosis. 2019;114:127-134. doi:10.1016/j. tube.2018.12.004 